\title{
Gregorio Magno y la psicología
}

\author{
Nicolás González Vidal \\ ESCUELA DE PSICOLOGÍA \\ UNIVERSIDAD DE LOS ANDES
}

Varios especialistas y estudiosos han destacado la penetración psicológica que Gregorio Magno demuestra en muchos de sus análisis concretos respecto del hombre y su conducta. Así por ejemplo, Vecchio y Casagrande, en su obra conjunta sobre los vicios capitales en la Edad Media, hablan de la «fineza psicológica», del «sutil análisis psicológico» y de la «atención minuciosa» ${ }^{1}$ con que dicho autor trata determinadas materias.

Por otro lado, yendo un poco más allá, hay quienes han hablado de la percepción y dotes psicológicas de Gregorio, pero en abstracto y no referidas -y, por tanto, quizá limitadas- a un caso concreto. En esta perspectiva, también por referir solo algunos ejemplos, Arborio Mella menciona «la atención instintiva sobre sí que le venía dada por su percepción psicológica» ${ }^{2}$, estimando como innata la atención por el interior ${ }^{3}$ que tal capacidad le daba.

Catry, por su parte, considera que la fineza psicológica de Gregorio, cuando menos, iguala a la de su maestro: «Sin poner en duda la finura psicológica del obispo de Hipona, se debe admitir que Gregorio, al menos,

1 Cfr. C. Casagrande - S. Vecchio, I sette vizi capitali. Storia dei peccati nel Medioevo (Torino 2000) 184 y 63, respectivamente.

2 E. Arborio Mella, «Rendere grazie in mezzo alle lacrime. Sofferenza e limite in Gregorio Magno» en Studium Biblicum Franciscanum <Yerûsalayim>: Liber annuus, 54 (2004) 295-320.

3 En relación con esta atención por lo interior, Straw indica: «Gregory wants fervently to know and control each step of the heart: every footprint must be scrutinized, every feeling sifted through the febrile hand of discretion». C. STRAw, Gregory the Great: Perfection in imperfection, (California 1988) 22. 
lo igualó» $»^{4}$, a su vez, Echavarría reconoce que «Gregorio muestra excelentes dotes psicológicas en obras como Moralia in Iob, de enorme influjo en Santo Tomás, y sobre todo en su Regla Pastorabi ${ }^{5}$; dotes que, en nuestra opinión, se manifiestan en mayor medida en la Regula, en cuanto a la estructura de la obra, pero no en cuanto a su lucidez y extensión, respecto a los cuales Moralia destaca aun más.

Finalmente, y solo por dar término a una enumeración que podría ser tediosa, Cristiani afirma: «La cultura monástica (...) desarrolla con Casiano y Gregorio Magno una capacidad de análisis psicológico que constituirá un patrimonio adquirido en la cultura de Occidente ${ }^{6}$, considerando a Gregorio como aquel que, junto a Casiano, dará origen y desarrollará una perspectiva psicológica no vista hasta entonces ${ }^{7}$.

Ahora bien, esta penetración psicológica se pone en ejercicio con tal lucidez y frecuencia en la obra gregoriana que, más que manifestaciones aisladas, dan lugar a un verdadero talante y casi configuran un determinado modo de acercarse a muchos tópicos. Y así, encontramos que muchos autores destacan no ya tal o cual análisis o desarrollo particular, sino que hablan, como Gillet, de un verdadero «sentido psicológico de Gregorio» ${ }^{8}$, que lo caracterizaría como tal. En un sentido bastante similar, esta vez en comparación con el tipo de reflexión de otros Padres como Agustín o Gregorio de Niza, señala: «La manera de Gregorio Magno es completa-

4 P. Catry, Parole de Dieu, Amour et Esprit-Saint chez saint Grégoire le Grand (Bégrolles-enMauges 1984) 178.

5 M. Echavarría, La praxis de la psicología y sus niveles epistemológicos en Santo Tomás de Aquino, (Girona 2005) 73, nota 40.

6 M. Cristiani, «"Ars Artium” La psicologia di Gregorio Magno» en Le trasformazione Della Cultura nella tarda Antichità, Atti del Convengo tenuto a Catania Università degli Studi, 27 sett.-2 ott. 1982, vol. I, Jouvence, (Roma 1985) 309-331;311-312.

7 En términos bastante similares, McGinn declara: «El papa Gregorio el Grande (590-604) tenía poco interés en las cuestiones filosóficas, pero nadie hizo más por la formación de la cultura monástica y su mentalidad, especialmente en las áreas que tienen que ver con la situación de la persona humana». B. McGINN - J. MEYENDORFF, (dir.), en colaboración con J. LECLERCQ, Espiritualidad cristiana. Desde los orígenes al siglo XII, título original Christian Spirituality. Origins to Twelfth Century, traducción de C. Conti (Buenos Aires 2000) 340.

8 G. LE Grand, Morales sur Job, livres 1 et 2, introduction et notes de Dom R. GiLlet, traduction de Dom. A. De Gaudemaris (Paris 1950) 54. 
mente diferente: no especulativa, sino psicológica» ${ }^{9}$, dando a entender que el modo mismo de abordar las distintas materias es psicológico. Evidentemente, ante este panorama, no es de extrañar que Gillet estime realmente excepcional a nuestro autor, precisamente, en vistas de la «agudeza de su sentido psicológico» ${ }^{10}$. Y, tan excepcional lo estima en este ámbito, que no duda en considerarlo «ante todo, moralista y psicólogo» ${ }^{11}$.

En este plano, Dagens llega a sostener que «su doctrina conserva siempre un carácter eminentemente concreto: en él encontramos toda una psicología del hombre cristiano» ${ }^{12}$; psicología que, por muy conectada que se encuentre con problemas morales a la vez que inserta en un contexto ascético, tiene -para Dagens- la categoría suficiente como para recibir tal denominación.

De este modo, habría quienes estarían dispuestos a dar un último paso, juzgando que el sentido, capacidad y penetración psicológicas de Gregorio son tales, que podríamos hablar, derechamente, de un Gregorio psicólogo ${ }^{13}$.

Con todo, definir si cabe -y en qué medida y bajo qué condicioneshablar de Gregorio como psicólogo no tiene mayor interés o utilidad. Al contrario, podría dar origen a innumerables confusiones y se correría el serio riesgo de descontextualizar tanto la figura como el pensamiento de nuestro autor, producto de comparaciones y paralelos, tal vez, forzados e indebidos.

Nos basta con que se reconozca que Gregorio manifiesta una sensibilidad y dotes psicológicas fuera de lo común y que, con mayor o menor profundidad y extensión, abordó -aunque sea indirectamente- determi-

9 G. Le Grand, Morales sur Job, introd., pág. 7. Apuntando a la misma idea, A. MelQUíADES declara que «Gregorio es más amigo de las fórmulas psicológicas que de las filosóficas». Gregorio Magno, Obras de San Gregorio Magno. Regla Pastoral. Homilías sobre la profecía de Ezequiel. Cuarenta homilías sobre los Evangelios, traducción por P. GALLARDo, introducción, notas e índices de A. Melquíades, (Madrid 1958) 61.

10 G. LE GRAnd, Morales sur Job, 11.

11 G. LE Grand, Morales sur Job, 11.

12 C. Dagens, Saint Grégoire le Grand. Culture et expérience chrétiennes, (Études Augustiniennes; Paris 1977) 434.

13 Schimmel, refiriéndose a los teólogos y moralistas en general, afirma: «The theologians and moralists who wrote so perceptively about our inclination to hurt others in order to satisfy ourselves and what we must do to change ourselves for the better were profound psychologist». S. Schimmel, The seven deadly sins. Jewish, Christian, and Classical Reflections on Human Nature, (New York 1992) 4. 
nados tópicos relacionados con este ámbito. Eso sí, debemos advertir que el interés que manifiesta por estas materias no se dirige a la psicología por ella misma, sino de modo indirecto y mediato.

Sin embargo, ha sabido apreciar-como pocos- la importancia de esta dimensión en la vida espiritual. Por lo mismo, aunque los desarrollos psicológicos que realiza nunca sean, para él, un fin en sí mismos y siempre se encuentren orientados a la praxis cristiana, no por eso dejan de estar presentes y de ser susceptibles de un análisis relativamente independiente.

Este Gregorio, dotado de un talento y finura psicológica nada comunes, es el que nos interesa considerar y, con lo dicho, solo hemos intentado mostrar que realmente existe. Tal como señala O’Donnell, «pocos podrán desautorizar al segundo Gregorio. Él es un maestro de vida espiritual y, si no completamente original (...), poseedor, en cambio, de una profunda comprensión del funcionamiento de la personalidad humana ${ }^{14}$, reconociendo que dicho Gregorio ${ }^{15}$, profundo conocedor de la personalidad y alma humanas, no solo existe, sino que difícilmente puede ser desconocido o desaprobado.

Un campo en el cual Gregorio Magno demuestra singular maestría y sutileza psicológicas está constituido por el reconocimiento de los diversos pliegues y facetas del mal y su capacidad para sacarlos a la luz, desenmascarándolos. Las verdaderas y más profundas intenciones, el disfraz de virtud bajo el que se presenta el vicio y las falsas apariencias son objeto de un incansable análisis bajo la mirada de nuestro autor, mostrando en ello sus mejores capacidades: «Gregorio emplea todo su arte de discernimiento en desenmascarar las trampas del mal bajo todas sus formas y en indicar los objetivos y los medios de la ascesis, que es como una primera etapa en el camino de Dios» ${ }^{16}$. Efectivamente, es todo un arte el que des-

14 J. O’Donnell, «The Holiness of Gregory» en Gregory the Great. A symposium, editor: J. CAVADini, (Indiana 2001) 62-81; 63.

15 En su artículo, O’DonNell considera la tipología que habla de «cuatro Gregorios», el segundo de los cuales sería al que nos estamos refiriendo. Los otros tres son, según O'Donnell: i.-) «the master of an early medieval Volkskatholizismus, a teller of miracle stories». J. O’Donneld, «The Holiness of...» 62; ii.-) «Gregory the Roman bureaucrat and administrator». Ibid. 63; iii.-) El cuarto Gregorio, propuesto por O’DonNell -y cuya ausencia en la tipología le causa sorpresa-, es «the debunked Gregory». Ibid. 64.

16 C. Dagens, Saint Grégoire le Grand. Culture et expérience chrétiennes, 434. 
pliega en desvelar el mal, consciente de que, mientras permanezca oculto, no cabe avance alguno hacia el bien.

Mientras el hombre no perciba el mal que hay en él o-incluso- estime ese mal como bien, producto de sus disfraces y ocultamiento, el camino de la virtud le estará vedado. Quien se considera justo, se encuentra en el peor de los escenarios y ni siquiera ha tomado lugar en el punto de partida. No en vano, como subraya Catry, «el texto de la primera Carta de San Juan "Si decimos: 'no hemos pecado', nos equivocamos y la verdad no está en nosotros" (I Jn. I, 8), es uno de los versículos de la Escritura que aparece con mayor frecuencia en Moralia $\rangle^{17}$. Con esta convicción, dirigirá sus esfuerzos a mostrar -con el modo concreto y práctico que lo caracteriza- que nadie puede considerarse justo. Así, ajeno a consideraciones teóricas, entrará de lleno en el análisis de las intenciones concretas, de los vicios ocultos, de las virtudes aparentes, tal como se muestran en la vida y experiencia cotidianas.

En este desenmascaramiento, jugará un papel fundamental la antítesis interior-exterior presente en su obra. El mal que salta a la vista no representa mayor dificultad, pues nadie puede desconocerlo. Los problemas surgen cuando se trata del mal oculto y solapado, el cual solo puede ser visto por quien tenga perfecta conciencia de que el interior es, muchas veces, distinto y hasta contrario a lo que aparece exteriormente. Y así, como destaca Dagens, para desenmascarar las contradicciones de los pecadores, nuestro autor recurrirá a la antítesis intus-foris, según la cual: «Intus designará la realidad profunda, a menudo escondida, pero la única importante y que proporciona criterios de juicio moral. Opuestamente, foris se aplicará a la apariencia, muchas veces engañosa y, detrás de la cual, se disimula el mal» ${ }^{18}$. Provisto de esta antítesis, Gregorio estará atento a distinguir ambos planos, siendo capaz de descubrir lo que se esconde en lo profundo del hombre, casi siempre tan distinto de aquello que se muestra en la superficie ${ }^{19}$.

17 P. CAtry, Parole de Dieu, Amour et Esprit-Saint chez saint Grégoire le Grand, 41. En nota al pie ( $\left.{ }^{\circ} 40\right)$, CATRY especifica: «Grégoire le cite cinq fois, uniquement d'ailleurs dans les livres 18 à 25: Mor. 18,39,40 (PL 76,64 B); 18,44,71 (80 C); 21,12,19 (201 B); 24,11,33 (306 B); 25,10,25 (336 D)».

18 C. Dagens, Saint Grégoire le Grand. Culture et expérience chrétiennes, 195.

19 No ya en Moralia, sino en sus Homilias sobre Ezequiel, Cristiani destaca la extrema sutileza con que la psicología de Gregorio, edificada -precisamente- en torno a esta 
Y no resulta extraño que nuestro autor tuviera presente esta antítesis, pues sus distintas experiencias y su capacidad de discreción, le dieron una sensibilidad especial para comprender las paradojas y dicotomías que presenta la realidad bajo todos sus aspectos. Y, de todas ellas -dada su condición de pastor- serán las ambivalencias presentes en la condición humana las que abordará con mayor detenimiento.

El bien y el mal no son fácilmente discernibles en su realización concreta. La buena y la mala intención, el vicio y la virtud no poseen contornos nítidos y claros que permitan distinguirlos cuando su lugar es el interior del hombre. De este modo, el corazón del hombre se transforma en un complejo escenario, donde «la relación entre los vicios y las virtudes no siempre es de oposición abierta. En el eterno conflicto entre el bien y el mal, sucede también que los vicios intentan mimetizarse y confundirse con el adversario, como había ya observado Gregorio» ${ }^{20}$, quien procura poner de manifiesto este dinamismo para lograr discernir uno de otro.

Concretamente, en Moralia, con ocasión de los más variados textos del libro comentado, van apareciendo tópicos que dicen relación directa con este desenmascaramiento del mal. Así, por ejemplo, Schreiner destaca la manera en que «después de condenar la herejía y la hipocresía de Elifaz, Bildad y Zofar, Gregorio encuentra en sus palabras verdaderas lecciones acerca de la falta de pureza en el hombre, del falso deseo de alabanza, de los peligros de la ira, de la importancia de las intenciones rectas y del engaño de la hipocresía ${ }^{21}$. Y, de este modo, van haciéndose cada vez más recurrentes las consideraciones de cuestiones como la ausencia de pureza, la búsqueda de reconocimiento, los efectos de las pasiones, la rectitud de intención, la hipocresía, la envidia ${ }^{22}$, etc.; todas ellas relacionadas con las motivaciones y dinamismos ocultos que, frecuentemente, dirigen la acción del hombre. El vicio se oculta a causa de la soberbia -el peor de

relación «intus»/ «foris», trata el mecanismo de la tentación. Cfr., M. CRISTIANI, «"Ars Artium" La psicologia di Gregorio Magno», 323-324.

20 C. Casagrande - S. Vecchio, I sette vizi capitali. Storia dei peccati nel Medioevo, 191.

21 S. SCHREINER, «"Where Shall Wisdom Be Found?”: Gregory’s Interpretation of Job» en The American Benedictine Review 39:3 (1988) 321-342; 338.

22 Dicho sea de paso, como reconocen Casagrande y Vecchio, Gregorio es el «padre occidental de la envidia», siendo el primero en incluirla en el listado de los vicios capitales, además de insistir particularmente en su dimensión social. Cfr. C. CASAGRANDE - S. Vecchio, I sette vizi capitali. Storia dei peccati nel Medioevo, 44-45. 
ellos-, afectando el propio juicio y sugiriendo justificación bajo título de racionalidad $^{23}$, con lo que la tarea no es nada fácil.

En efecto, al compás de estas cuestiones, se desenvuelven análisis finos y detallados que prueban la penetración psicológica con que Gregorio desentraña las escondidas dimensiones del mal. Aparece así, uno de los tópicos más característicos en torno al ocultamiento del mal: el de la hipocresía. Quizá, nadie hasta el momento había dado un lugar tan importante a este vicio como Gregorio ${ }^{24}$, con quien -de hecho- entra la hipocresía en la filiación de la soberbia ${ }^{25}$.

En la hipocresía se ponen en juego casi todos los dinamismos que hemos mencionado hasta ahora. El vicio se disfraza, el mal se oculta y la virtud se finge, produciéndose, en definitiva, una casi total contrariedad entre el exterior y el interior. Pues como refiere Dagens, en esta materia Gregorio recurre nuevamente a su «antítesis favorita» ${ }^{26}$. Nuestro autor, de esta manera, enfrenta con decisión y lucidez la tarea de manifestar los vicios ocultos, ya que, para combatirlos, primero hay que reconocerlos e identificarlos. Y el empeño y precisión con que lo hace es digno de atención, pues «Gregorio pone tanto empeño y perspicacia en denunciar esta sancta species de los hipócritas y de los falsos doctores, como el que pone en demostrar que los vicios se esconden, muy a menudo, bajo la apariencia de las virtudes ${ }^{27}$; siendo necesario reconocer que lo hace con una perspectiva y acierto admirables. Y es que no cabría esperar tanta dedicación al problema de la hipocresía si no se tiene presente que, a los ojos de Gre-

23 Así, por ejemplo, describe esta mecánica Casagrande, a la luz de las consideraciones de Gregorio: "Cosí dal seno della superbia si genera la prima delle sue figlie: la vanagloria. Suadente come tutti i vizi, si insinua nel cuore ormai vinto e gli suggerisce giustificazioni nono prive di una parvenza di razionalità [y cita texto Moralia XXXI, XLV,90]”. C. Casagrande - S. Vecchio, I sette vizi capitali. Storia dei peccati nel Medioevo, pág. 7.

24 Para Cavalcanti, el tratamiento que Gregorio hace de este vicio en Mor. VIII, XLII, 66 a VIII, LI, 87 es tal, que considera estas páginas un "autentico trattatello sull'ipocrisia nel senso di mancanza di autenticità nella presunta practica della virtù e nella vita spirituale in genere (...)”. E. CAVALCANTI, «Interiorità e identità personale nel commento a Giobbe (Moralia) di Gregorio Magno», Annali di storia dell' esegesi, 22/1 (2005), 11 35,23 , nota 49 .

25 Cfr. Mor. XV, VI, 7 y, también, C. Casagrande - S. Vecchio, I sette vizi capitali. Storia dei peccati nel Medioevo, pág. 21.

26 C. Dagens, Saint Grégoire le Grand. Culture et expérience chrétiennes, pág. 196.

27 C. Dagens, Saint Grégoire le Grand. Culture et expérience chrétiennes, 197. 
gorio Magno, dicho vicio es exactamente el polo opuesto de la sencillez propia de la santidad ${ }^{28}$.

Como puede apreciarse, Gregorio no alberga mayores ilusiones en relación a la condición y conducta humanas. Al contrario, en cada bien encuentra un fondo de mal que hace del primero algo ilusorio ${ }^{29}$. Tanto así que, siguiendo el hilo de su discurso, se corre el riesgo -dice Gillet- de caer en el desaliento ${ }^{30}$. Este riesgo solo se evita si se comprende que el énfasis dado a las dimensiones del mal, junto con deberse a una mirada realista y sincera, tiene por objeto suscitar una lucha decidida, precisamente, a la vista de la categoría y dimensiones del mal que se enfrenta.

Ahora bien, bajo esta perspectiva, puede afirmarse que nuestro autor lleva a cabo una sistemática labor de desenmascaramiento del mal, la cual es tan recurrente a lo largo de las páginas de Moralia, que cabe postular - con Dagens- la existencia de una «retórica gregoriana» dirigida a tal fin. $\mathrm{Y}$ así, con ocasión de un texto de esta obra en que se describen las distintas manera en que unos y otros caen en la arrogancia [Mor., 22, 7, 15], dicho autor señala: «nonnulli [algunos] no se relaciona, solamente, con el vocabulario de la descripción psicológica, de los análisis morales o de los consejos pastorales. Forma parte de la retórica gregoriana; sirve para presentar comportamientos similares, a través de los cuales, se manifiesta un mismo vicio» ${ }^{31}$. Ciertamente, el uso del nonnulli, no se limita a puntuales referencias de índole psicológico o moral, sino que adquiere, en Gregorio, la categoría de una verdadera fórmula al servicio de esta retórica orientada a desenmascarar todo tipo de apariencias, manifestando los vicios que, tras ellas, se ocultan.

Frente a tales condiciones y cualidades, no parece fuera de lugar preguntarse si Gregorio podría ser considerado un «maestro de la sospecha»,

28 En palabras de DAGENS, «si l'hypocrisie est le triomphe de l'apparence, la sainteté est donc un effort qui concerne l'intérieur et l'extérieur, ainsi que leur accord mutuel». C. Dagens, Saint Grégoire le Grand. Culture et expérience chrétiennes, 197.

29 Sin duda, Gregorio es plenamente consciente, como advierte Hildebrand, de que «no hay nada humano que no pueda ser pervertido ni falsificado y realmente, cuanto más elevado es algo, tanto peor es su perversión y falsificación: Corruptio optimi pessima». D.von Hildebrand, El corazón. Un análisis de la afectividad divina y humana, título original, The Heart, traducción de J. Burgos, (Madrid $\left.{ }^{5} 2005\right) 51$.

30 G. LE Grand, Morales sur Job, introd., 65.

31 C. Dagens, Saint Grégoire le Grand. Culture et expérience chrétiennes, 108. 
tal como Ricoeur ha calificado a Marx, Nietzsche y Freud ${ }^{32}$. Según el pensador francés, «el filósofo contemporáneo se encuentra con Freud en los mismos parajes que halla a Nietzsche o Marx; los tres se erigen ante él como protagonistas de la sospecha, como desenmascaradores. Un problema nuevo ha nacido: el del engaño de la conciencia, de la conciencia como engaño» ${ }^{33}$. $\mathrm{Y}$, ciertamente, en razón del contexto y la magnitud del problema, cabría juzgarlo como inédito, pero si se atiende a algunos paralelos, es posible tal vez encontrar algunos antecedentes.

En efecto, entre los méritos de estos autores, hay algunos que también posee Gregorio Magno en lo que se refiere al análisis de la virtud. Como advierte Pareyson, «para que su descripción resulte no solo interesante, sino también verdadera y fecunda, la virtud debe ser hoy sometida a esa "técnica de la desconfianza" o "escuela de la sospecha" en la que nuestra edad ha derrochado tanta maestría. Hoy no existe ningún bien que no aparezca minado por la hipocresía (...) La virtud posee un aspecto de fango y animalidad del que puede ser muy bien tanto su superación como su cobertura: ¿quién puede decir si una virtud vence verdaderamente o si tan solo disimula el mal del cual emerge, si lo trasciende purificándolo o si no es más que una cómplice canalla y solapada del mismo?» ${ }^{34}$. Ahora bien, en esta técnica de la desconfianza y de la sospecha ¿solo nuestra edad ha mostrado maestría? ¿Acaso Gregorio no es, también, plenamente consciente de que todo bien se encuentra asediado por la hipocresía? ¿No hemos destacado que, para nuestro autor, las apariencias difuminan los límites entre el bien y el mal, dotando a la virtud de cierta ambigüedad en razón de que, muchas veces, no es más que un disfraz que disimula el mal?

En este sentido, Gregorio presenta ciertas afinidades con estos maestros de la sospecha y, salvando ciertas diferencias de fondo, hasta podría contarse entre ellos. El propio Ricoeur, afirma que «la categoría fundamental de la conciencia, para los tres [Marx, Nietzsche y Freud], es la relación oculto-mostrado o, si se prefiere, simulado-manifiesto» ${ }^{35}$; catego-

32 Cfr. P. Ricoeur, Freud: una interpretación de la cultura, -título original, De l'interprétationessai sur Freud-, traducción de A. SuÁrez (México $\left.{ }^{12} 2007\right) 32$.

33 P. Ricoeur, El conflicto de las interpretaciones. Ensayos de hermenéutica, -título original, Le conflit des interprétations-, traducción de A. FALCON (Buenos Aires 2003) 95.

34 L. Pareyson, Dostoievski: Filosofía, novela y experiencia religiosa, -título original, Dostoevskij: filosofia, romanzo ed esperienza religiosa-, traducción y prólogo de C. GIMÉnEz (Madrid 2007) 207-208.

35 P. Ricoeur, Freud: una interpretación de la cultura, 34. 
ría que, como hemos señalado, sobresale también en Gregorio. De este modo, si lo que une a estos tres pensadores radica en esta consideración, cabría, en cierto sentido, sumar a Gregorio -con todas las prevenciones del caso- a dicha escuela.

$\mathrm{Y}$ este paralelo no resulta inoportuno si se tiene a la vista el que ha establecido Juan Pablo II entre la hermenéutica de la sospecha y la hermenéutica bíblica. Según este paralelo, habría una significativa convergencia entre estas hermenéuticas, ya que ambas acusan y juzgan el corazón del hombre a causa de lo que el lenguaje bíblico denomina la «triple concupiscencia». Específicamente, «en la hermenéutica nietzscheana, el juicio y acusación al corazón humano corresponde, en cierto sentido, a lo que en lenguaje bíblico se llama "soberbia de la vida"; en la hermenéutica marxista, a lo que se llama "concupiscencia de los ojos"; en la hermenéutica freudiana, a lo que se llama "concupiscencia de la carne" "»6; correspondencias a partir de las cuales Juan Pablo II concluye: «La convergencia de estas concepciones con la hermenéutica bíblica sobre el hombre, consiste en el hecho de que, al descubrir en el corazón del hombre la triple concupiscencia, también nosotros pondríamos bajo sospecha al corazón ${ }^{37}$. Y bien podría considerarse a Gregorio situado en esta hermenéutica bíblica, haciéndose también acreedor de esta convergencia; y acreedor de un modo especial, porque no se limita a asumir la antropología bíblica, sino que, de hecho, formula esta acusación sistemática y pormenorizadamente. Así, en el caso de Gregorio, la convergencia se daría en cuanto al fondo, porque reconoce las tres concupiscencias en el corazón del hombre, y a su vez en la forma, ya que busca sacarlas a la luz caso a caso, con una constancia excepcional.

Evidentemente, como destaca por otra parte Juan Pablo II, junto con esta convergencia, debemos reconocer una importante divergencia, también aplicable plenamente a Gregorio, y es que: «Las palabras de Cristo en el sermón de la Montaña (Mt. 5, 27-28) son de tal calibre que, aun mostrando toda la realidad del deseo y de la concupiscencia, no permiten que esta se erija en el criterio absoluto de la antropología y la ética, es decir, en el núcleo mismo de la hermenéutica del hombre» ${ }^{38}$. La presencia del mal

\footnotetext{
36 JuAn Pablo II, La redención del corazón. Catequesis sobre la pureza cristiana, (Madrid $\left.{ }^{3} 2002\right)$ 154-155.

37 Juan Pablo II, La redención del corazón. Catequesis sobre la pureza cristiana, 154-155.

38 Juan Pablo II, La redención del corazón. Catequesis sobre la pureza cristiana, 154-155.
} 
en lo profundo del hombre justifica la sospecha y la acusación respecto de él, pero no permite que esta acusación sea la última palabra, pues en el hombre también hay, en virtud de la gracia y como consecuencia de la redención, verdadera bondad. Y efectivamente: «Las palabras de Cristo testimonian que la fuerza originaria (por tanto, también de la gracia) del misterio de la creación, se convierte para cada uno en fuerza (es decir, en gracia) del misterio de la redención. Esto se refiere a la naturaleza misma, al substrato mismo de la humanidad de la persona, a los impulsos más profundos del corazón ${ }^{39}$. Hay así, en el hombre, otra realidad además del mal y otras posibilidades que las que se siguen del mismo. En él habita también la gracia, por la que está llamado, capacitado y destinado al bien verdadero.

De este modo, hemos expuesto en qué sentido vemos en Gregorio Magno un «maestro de la sospecha». Y, a pesar de las profundas diferencias que pueden señalarse $-\mathrm{y}$, seguramente, caben otras más-, nos ha parecido relevante destacar este paralelo en vistas a la comprensión de las posibilidades que presenta el Gregorio psicólogo ${ }^{40}$.

Con todo lo dicho, podemos concluir que nuestro autor no aborda determinados tópicos de alguna connotación psicológica de modo simplemente aleatorio y como si solo fuera el resultado de la amplitud y dispersión de las materias tratadas, las cuales lo conducirían, de vez en cuando, a los dominios de la psicología. Al contrario, su interés por el «hombre interior», con sus reales móviles e intenciones, lo conduce de modo permanente al plano psicológico, a tal punto, que no constituye una exageración hablar del Gregorio psicólogo.

39 JuAn Pablo II, La redención del corazón. Catequesis sobre la pureza cristiana, pág. 157.

40 MoOrHeAd, en esta misma línea, considera a Gregorio un verdadero maestro en el ámbito psicológico: «some process of analysis of himself and others which we cannot trace made Gregory one of the masters in examining the motions of human heart». J. Moorhead, Gregory the Great (New York 2005) 89. 
Resumen: Este artículo investiga la preocupación por el hombre interior en Gregorio Magno, a fin de mostrar, apoyado de abundantes referencias bibliográficas, cómo esta preocupación sistemática le conduce permanentemente al plano psicológico, al punto de que sería posible hablar del Gregorio psicólogo.

Palabras clave: Gregorio Magno, hombre interior, psicología.

Abstract: This article investigates the concern for the inner man in Gregory the Great, in order to show, supported by abundant bibliographical references, how this systematic concern constantly leads him to the psychological plane, to the point that it would be possible to speak of Gregory the psychologist.

Key words: Gregory the Great, inner man, psychology. 